which, further, should be provided with all that is necessary for the establishment of the stations, the safety and the subsistence of the observers, should not leave those regions before bringing the mission to Tahiti, where our envoyés would find means of transport for their return, either by the way they went, or (which would seem preferable), by way of Australia.

\section{THE TRANSIT OF VENUS ON WEDNESDAY,} DECEMBER 6

$A \mathrm{~T}$ the Transit of Venus in 1874 the tables of the A planet prepared by Prof. Hill appeared to have a decided advantage over those of Leverrier. The correction to the tabular place deduced from the observations of the transit is in close accordance with that shown by a meridian observation at Washington on the day preceding the phenomenon. Although the entire discordance was not regatived by the tables of Prof. Hill, they went far towards removing it in 1874, and as the coming transit (December 6) will take place in nearly the same point in the planet's orbit, we shall assume in what follows, that the tables of the American astronomer will again be fairly correct. Prof. Newcomb assumes and probably $n$ ith much reason, that the error of Leverrier's tables will prove to be an increasing one, and is therefore inclined to apply a still larger correction to the place deduced from them. It may be mentioned that the calculations of the transit in the Nautical Almanac, the Connaissance des Temps, and the Berliner Astronomisches Jahrbuch, depend upon Leverrier's tables. For the diameter of the planet we adopt that found by Prof. Auwers from heliometric measures in Egypt during the last transit, combining it with the diameler of the sun, inferred by Leverrier from his discussion of the transits of Mercury.

Direct calculations for Greenwich, Edinburgh, and Dublin give with the elements so obtained the following Greenwich mean times of the first external contact, and the respective angles from the sun's vertex for direct image :-

$$
\begin{aligned}
& \begin{array}{cccccccccc}
\text { Greenwich } & \ldots & \ldots & \text { h. } & \text { m. } & \text { s. } & & & \text { o } & \multicolumn{2}{c}{\cdot \mathbf{2}} & \ldots & \ldots & \text { I } 26 & 59 \cdot 4
\end{array}
\end{aligned}
$$

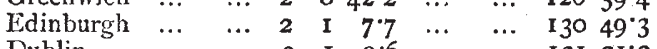

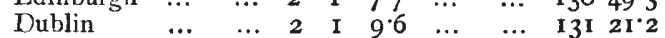

For a limited area like that of these islands we may apply to these times and angles, the method of distribution of predictions given by Littrow, and subsequently by Woolhouse. Putting the latitude of any place within the above area $=50^{\circ}+\mathrm{L}$, and its longitude in minutes of time $=\mathrm{M},+$ if east of Greenwich, - if west, we get the following equations:-

G.M.T. of first ex-

ternal contact $\ldots\}=2 \mathrm{~h} .0 .62 \mathrm{~m} .+[8 \cdot 7453] \mathrm{L}-[8 \cdot 1402] \mathrm{M}$. Angle from sun's ver- $>$

tex, direct image... $\}=126^{\circ} \cdot 3+\left[9^{\circ} 669\right] \mathrm{L}-\left[9^{\cdot 136}\right] \mathrm{M}$.

The quantities within the square brackets are logarithms, but of course if preferred the factors for $L$ and $M$ may be expressed as numbers. As an example of the application of these formulæ, suppose the time of first contact and the corresponding angle are required for Norwich, the position of which place may be taken in latitude $+52^{\circ} 38^{\prime}$, longitude $1^{\circ} 18^{\prime}$ or $+5 \mathrm{~m}$. 12s., we have then

$$
\begin{aligned}
& \mathrm{L}=+2^{\circ} .633 \mathrm{M}=+5^{\circ} .20 \mathrm{~m} \text {. }
\end{aligned}
$$

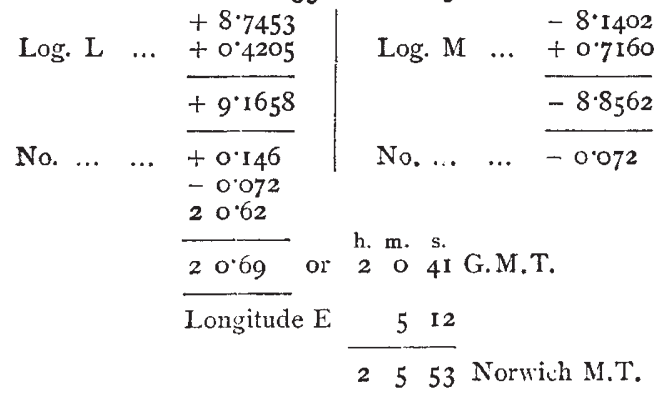

For the angle-

$$
\begin{aligned}
& +9.669-9^{\circ} \cdot 136 \mid+1 \cdot 23 \\
& \begin{array}{l|l|l}
\text { Log. L + 0.42I } & \text { Log. M + 0.716 } & -0.71
\end{array} \\
& \begin{array}{l|l|l}
\hline+10.090 & -9.852 & \frac{126.3}{126.8 \ldots} \text { angle from vertex. }
\end{array}
\end{aligned}
$$

So that according to the calculation the limb of the planet comes into first contact with that of the sun at $53^{\circ}$ from his lowermost point towards the left, as we view the phenomenon with the naked eye. It will be remarked that there is less than a half minute difference in absolute time between Greenwich and Dublin, and considering the possibility of error of many seconds in any prediction that can be made for geometrical contact and the difficulty of always determining what is geometrical contact in the observations, our formula for time of first contact is more than a sufficient one.

For first internal contact, it may be assumed that $2 \mathrm{I}$ minutes have to be added to the time of external contact at any place in these islands; while for the angle from N. point of first external contact may be taken in all cases $147^{\circ}$.

In the national ephemerides the times of the contacts are given for a particular meridian as they would be noted at the centre of the earth, and formulæ are appended to reduce these geocentric times to any point upon the earth's surface. It is obvious that where, as in a transit of Venus, predictions are required for such widely distant stations, this method possesses the greatest convenience.

\section{NOTES}

THE following are the Lecture arrangements at the Royal Institu. tion for the ensuing Session:-The Christmas Lectures will be given hy Prof. Tyndall, on Light and the Eye. Before Easter-Prof. W. C. Williamson on the Primeval Ancestors of Existing Vegetation, and their Bearing upon the Doctrine of Evolution; Prof. R. S. Ball, four lectures on the Supreme Discoveries in Astronomy; Prof. Dewar, nine lectures on the Spectroscope and its Applications; Mr. R. Bosworth Smith, four lectures on Episodes in the Life of Lord Lawrence; Dr. W. H. Stone, three lectures on Singing, Speaking, and Stammering; Mr. H. H. Statham, two lectures on Music as a Form of Artistic Expression. After Easter-Courses will be given by Professors Tyndall, McKendrick, A. Geikie, and Turner (of St. Petersburg). The Friday Evening Discourses will probably be given, among others, by Mr. R. B. Smith, Dr. G. J. Romanes, Sir W. Thomson, Mr. M. D. Conway, Prof. W. C. Williamson, Mr. W. H. Pollock, and Prof. Tyndall.

A committee, consisting of the Right Hon. J. T. Ball, LL.D., D.C.L., the Very Rev. W. Reeves, D.D., Dean of Armagh, J. L. E. Dreyer, Ph.D., Astronomer of Armagh Observatory, has been appointed by the Governors of the Armagh Obsirvatory to raise a fund for the purpose of erecting a memorial instrument in the observatory at Armagh, where the late Rev. Dr. Robinson spent fifty-eight years, engaged in those scientific investigations with which his name will be for ever associated. The Committee addresses its appeal not only to the inhabitants of Ulster, or of Dublin, but to Robinson's friends and adwirers all over the United Kingdom. The services rendered to astronomy by Dr. Robinson are well known, and doubtless many of our readers will be glad to aid in paying a tribute to his memory. It is proposed that the memorial take the form of an equatoreal refractor, say of eight or nine inches aperture, which could be had for about $500 \%$, and could find room in one of the existing domes at Armagh. With such an instrument, much valuable and interesting work could be done. Subscriptions should be sent to Dr. J. L. E. Dreyer, Observatory, Armagh. 
WE regret to announce the death, on November 24, of Mr. Andrew Pritchard, M.R.I., F.R.S. Edin., \&c., of Highbury, London, whose name will be best remembered in connection with several improvements of the microscope, the use of "test objects," and as being the author of "A History of Infusoria," the fourth edition of which, enlarged to nearly 1000 pages, was published in $\mathrm{r} 86 \mathrm{I}$. Born in London in December, 1804, he was almost entirely brought up by his grandfather, one of the chief cashiers in the Bank of England. On the foundation of the Mechanics' Institution in Southampton Buildings, by Dr. Birkbeck, Mr. Pritchard entered as a student. The inicroscope was then a very imperfect instrument, and $\mathrm{Mr}$. Pritchard worked hard at the achromatisation of lense:, and was the first to propose to take advantage of the high refracting power of the diamond, ruby, and sapphire for the manufacture of single lenses, these giving good definition without the coloured borders incidental to ordinary flint glass. Between the years 1829 and 1837 he published several works on the microscope, in which he was aided by Dr. Goring, particularly the "Microscopic Illustrations," "Micrographia," and the "Microscopic Cabinet," for which several good plates were prepared. In the year $1836 \mathrm{Mr}$. Pritchard was elected a Member of the Royal Institution, being proposed by Faraday, and in the previous year joined the British Association at Dublin, taking part in the deliberations of this body until comparatively recent times. In 1873 the Royal Society of Edinburgh .conferred upon him their fellowship, in recognition of his scientific attainments, as evidenced by his great work, the "History of Infusoria," a memorial of patient industry and biological research.

The Lancashire friends of the late Prof. Jevons are to hold a meeting at the Manchester and Salford Bank on Thursday next, to consider a proposal for a Jevons memorial. It has been suggested that an appropriate form of the memorial would be the establishment of a Professorship of Political Economy at the Victoria University, Manchester. Prof. Jevons was a Lancashire man, and was associated for many years with the Owens College and with the Manchester Statistical Society.

Mr. Barnard, of Nashville, Tennessee, and Prof. Wilson, of the Cincinnati Observatory, both noticed that the nucleus of the comet had separated into three fragments on the morning of October 5. While this separation was not observed at other o'servatories, probably owing to cloudy weather, we learn by the last steamer from Central America, that on the same morning the comet, as visible to the naked eye, at Escuintla, Guatemala, was divided into five distinct bodies, thus leading many to suppose that a whole family of celestial visitants had suddenly appeared. Subsequent observations in different parts of the world have led to the belief that the fragments were re-united. This statement appears in the Panama Star and Herald.

THE transit of Venus, on December 6, will be observed at Paris with the helio itat in several places, to exhibit the phenomenon to a large audience. M. Joubert, director of the $\mathrm{Ob}$ ervatoire Populaire of the Trocatero, is taking steps for that purpose, and will send out special invitations. Lectures will be delivered during the transit. M. Janssen, before leaving for Oran, left instructions for similar observations to be exhibited before a number of visitors at Meudon Observatory. A requisition has been sent to M. Bouteiller, the president of the Municipal Council, asking him to order that the leading pupils of public schools and their principal teachers should be invited to Montsouris Observatory in order to witness the transit.

WE are glad to learn that Pruf. Mendeleeff has published a new edition (the fourth) of his "Principles of Chemistry." The new edition is thoroughly revised, and contains many important additions and modifications, bringing it up to the latest data of science. The high standard of this book is well known. The aims the author has pursued may be seen in the following words of his preface: "By comparing the past of the science with the future, the particulars with the generalisations, and our necessarily limited experience with our natural tendency towards the infinite, and by refraining from asking the student to accept without test any doctrine, however attractive, I tried to develop in the reader the faculty of independent judgment on scientific subjects which is necessary for a true use of science, and for acquiring the possibility of working for its further development." The work may be regarded as not merely a text-book of chemistry, but an exposition of the methods of natural science altogether.

ALGERIA is becoming increasingly popular as a winter resort for invalids affected with chest disease ; but probably not many of our readers are aware that in the same easily accessible country gout and rheumatic patients may find what is scarcely to be met with in Europe, a comfortable residence with abundance of waters adapted to their special complaints. At Hammam R'Irha, about sixty miles south-west of Algiers and fifteen miles in a direct line from the coast, such patients will find waters both for bathing and drinking comparable with those of the best European resorts, and in addition a climate which renders outdoor exercise a pleasure all the winter through. Hammam R'Irha is beautifully situated among the hills of an outlying spur of the Lesser Atlas, and we understand has every possible convenience and comfort that invalids can require. Naturally enough the people of Algiers look with some jealousy on this pleasant spot as a rival, and attempt we believe to ignore it; but in the opinion of the highest authorities on the subject of climate and waters, no place can equal Hammam R'Irha as a winter resort for gout and rheumatic patients. As it becomes better known we are sure it will grow in favour, especially with English and Americans, who will find on the spot competent medical advice. The station is within three or four hours' rail of Algiers.

THE remarkable phenomenon which was seen on Friday week in several parts of this country, was also seen in Sweden. At Eskibstuna, 54 miles south of Stockholm, it was observed three hours after sunset in the western heavens, it being dark at the time, about $45^{\circ}$ above the horizon, and was then hidden in a lurid cloud of purple colour. When approxching the zenith an oblong object, somewhat resembling a bow, became distinctly visible, which gradually passed out of sight. The stars were visible through the object. The moon in her first quarter shone faintly in the south, $45^{\circ}$ elevation above the horizon, while heavy clouds covered the eastern and northern skies. Auroræ were frequent and intense all over Scandinavia during the week.

Herr Bernhard Blechmann, a pupil of Prof. Stieda, of Dorpat, has been making researches on the anthropology of the Jews. He took 100 Jews of West Russia and the Baltic Provinces, and as a result of his observations, he finds that there are both blonde and dark Jews of the primitive type, that Jews have narrower chests than Europeans under similar conditions; that there are two types, Spanish and Germano-Polish; and that they appear to be brachycephalic.

THE third German "Geographentag" will be held at Frankfort on March 29-3 1,1883 . As at former meetings, both the scientific and educational aspects of geography will receive attention, and intending contributors of papers should communicate with Prof. Rein, Marburg, before the end of January. There will, as usual, be an exhibition of teaching matériel in geography, which will be open for two or three weeks.

IMMENSE forest fires are reported from the neighbourhood of St. Petersburg. Near Pawlowsk and the villages Skolpino, Stepanowka, and Podberesche near Gatchina, then along the 
Warsow railway line between Pljusse and Pleskau, also along the Moscow Railway line the forest was on fire. Thousands of people had been ordered out to try and extinguish the flames, but all attempts in this direction proved futile, the only thing that could be done was to confine the limits of the fires.

DR. KING, the Superintendent of the Royal Botanic Gardens, Calcutta, has recently issued his report for the year 1881-82. The Calcutta Garden may be said to be the centre of botanical work in India, and none can probably claim a greater antiquity, as the report before us is stated to be the nine! $y$-fifth annual report of these Gardens. Like its predecessors the report opens with a description of the changes and improvements in the Garden itself, points which are, of course, only of local interest. On the subject of india-rubber yielding plants-a subject of very great importance-Dr. King says: "Clara rubber (Manihot Glaziovii) continues to grow well here; our trees are beginning to seed, and from their produce I was able to distribute during the year a good many seedlings to tea-planters in Assam, Chittagong, and elsewhere. A species of Landolphia, which is one of the sources of the rubber collected in Eastern Africa, has (thanks to the exertions of Sir John Kirk, Her Majesty's Consul-General at Zanzibar) been introluced to the Garden. From the seeds sent by Sir John Kirk a number of young plants have been raised, and these at present look very healthy. The culivation of the plant yielding Para rubber (Hevea brasiliensis) has been abandoned, as the Bengal climate proves quite unsuitable for it. Of Castilloa, another South American rubber-yielder, we have as yet only eight plants, but it is being propagated as fast as possible.". Another important subject is that of the production of materials for paper-making, and of these plantain fibre seems to have occupied some attention. It seems that during the dry month;, simple exposure of the sliced stems to the sun is a sufficient preparation for the paper-maker, provided the paper-mill be on the spot. What is still wanted is some cheap mode of removing the useless cellular tissue, so that the fibre may be shipped to England without the risk of fermentation during the voyage. The cultivation of the plantain for its fruit is so universal over the warmer and damper parts of Intia, and its growth is so rapid, that the conversion into a marketable commodity of the stems at present thrown away as useless would be an appreciable addition to the wealth of the country. The paper mulberry of China and Japan (Broussonetia papyrifera) is being tried in the Garden, as well as in the Cinchona plantations in Sikkim, as it is well known that the bark yields a splendid paper material. A plant which appears to be at present unknown, but which Dr. King thinks will prove a species of Erinphorum, is also favourably reported upon. Under the head of "Other Economic Plants," mahogany, the rain-tree, and the Divi Divi, are said to be in considerable demand. A large interchange of seeds and plants has been effected during the' year, with other parts of India, as well as with England and the Colonies.

No further news of the wreck alleged to have been seen near the Island of Waigatz has come to hand. Capt. Burmeister, of the Louise, who parted from the Dijmphna and the Varna in September last, is of opinion that the vessel seen is the Varna in ber winter-quarters, simply with masts and yards lowered, which seem to be corroborated by the recent discovery, that the original message says zest of Waigatz Island, where the wreck could not have drifted.

PAKTS II to I6 of Dr. Chavanne's edition of Balbi's Geo. graphy (Vienna, Hartleben) have appeared; they are largely devoted to the Austro-Hungarian monarchy.

WE need scarcely mention that Oxford is the seat of the New Science Club, to the meeting at Trinity College in connection with which we referred last week.
In the last sitting of the Syndicat d'Electricite M. Jablochkoff described a new element which he has invented, and which consists of sodium for the electro-positive plate, the negative being, as usual, carbon. M. Jablochkoff does not use any exciting liquid but merely sends into his elements by the instrumentality of an aspirator, a current of air saturated with moisture. He says that soda is dissolved and falls to the bottom of the box where his elements are kept so that it may be easily collected and sold at a high price, being pure except for a smali quantity of carbonate and of nitrate. According to his statement the electromotive force of this element is about 4 volts.

THE additions to the Zoological Society's Gardens during the past week include a Green Monkey (Ceriopithecus callitrichus $\$$ ) from West Africa, presented by Mrs. Gretton ; a Northern Lynx (Felis lynx) from the Carpathian Mountains, presented by the Count Constantin Branicki ; an Isabelline Lynx (Felis isabellina) from Tibet, presented by Capt. Baldock; a Forster's Milvago (Milvago australis) from Falkland Islands, presented by Dr. A. M. McAldonie ; an Annulated Snake (Leptodira annulata) from Honduras, presented by Mr. R. E. Seabrooke; a Short-tailed Wallaby (Halmaturus brachyurus \&) from West Australia, three Blue-crowned Hanging Parrakeets (Loriculus galgulus) from Ceylon, deposited; a Moloch Monkey (Callithrix moloch) from Brazil, two Snowy Owls (Nyctea nivea of o), European, a Shore Lark (Eremophila alpestris), British, purchased; a Great Bustard (Otis tarda), European, received in exchange.

\section{ON THE TRANSITS OF VENUS. ${ }^{\mathrm{T}}$}

TRANSITS of Venus usually occur in pairs; the two transits of a pair being separated by only eight years, but between the nearest transits of consecutive pairs more than a century elapses. We are now on the eve of the second transit of a pair, after which there will be no other till the twenty-first century of our era has dawned upon the earth, and the June flowers are blooming in 2004. When the last transit season occurred the intellectual world was awakening from the slumber of ages, and that wonderous scientific activity which led to our present advanced knowledge was just beginning. What will be the state of science when the next transit season arrives God only knows. Not even our children's children will live to take part in the astronomy of that day. As for ourselves, we have to do with the present, and it seems a fitting occasion for noticing briefly the scientific history of past transits, and the plans for observing the one soon to happen.

When the Ptolemaic theory of the solar system was in vogue, astronomers correctly believed Venus and Mercury to be situated between the Earth and the Sun, but as these planets were supposed to shine by their own light, there was no reason to anticipate that they n ould be visible during a transit, if indeed a transit should occur. Yet, singularly enough, so far back as April, 807, Mercury is recorded to have been seen as a dark spot upon the face of the Sun. We now know that it is much too small to be visible to the naked eye in that position, and the object observed could have been nothing else than a large sunspot. Upon the establishment of the Copernican theory it was immediately perceived that transits of the inferior planets across the face of the Sun must occur, and the recognition of the value of transits of Venus for determining the solar parallax was not long in following. The idea of utilizing such transits for this purpose seems to have been vaguely conceived by James Gregory, or perhaps even by Horrocks; but Halley was first to work it out completely, and to him is usually assigned the honour of the invention. His paper, published in 1716 , was mainly instrumental in inducing the governments of Europe to undertake the observations of the transits of Venus of 1761 and 1769 , from which our first accurate knowledge of the Sun's distance was obtained.

When Kepler had finished his Rudolphine tables they furnished the mean; of predicting the places of the planets with some approach to accuracy; and in 1627 he announced that

I An address delivered before Section A of the Amrican Association for the Advancement of Science, on August 23, 1882, by Prof. Wm. Harkness, Chairman of the Section, and Vice President of the Association. 